\title{
Influência do manejo alimentar no ganho de peso e no desempenho reprodutivo de novilhas de corte
}

\section{André Luís Menegaz ${ }^{1}$, José Fernando Piva Lobato ${ }^{2}$, Antonio Carlos Gonçalves Pereira ${ }^{3}$}

\author{
1 Programa de Pós-graduação em Zootecnia - UFRGS - RS \\ 2 Departamento de Zootecnia, Faculdade de Agronomia/UFRGS. Caixa Postal 15.100, CEP: 90001-970 - Porto Alegre, RS. \\ ${ }^{3}$ GAP - Genética Agropecuária - Uruguaiana, RS.
}

RESUMO - Avaliaram-se os efeitos de três manejos alimentares nos meses de inverno (CN - campo nativo; CNS - campo nativo + suplementação; CNM - campo nativo melhorado) e de três grupos de peso (leve; média; pesada) no desempenho reprodutivo subseqüente de novilhas Brangus com primeiro serviço aos 24/27 meses de idade. Os manejos alimentares determinaram diferenças no ganho médio diário (GMD) durante o inverno (0,261; 0,376 e 0,679 kg/dia) e no peso vivo ao início do período reprodutivo (302,8; 317,8 e 330,7 kg para CN, CNS e CNM, respectivamente). A taxa de prenhez (TP) não diferiu entre os manejos alimentares (88,3; 93,3 e 95,0\% para CN, CNS e CNM, respectivamente). Entretanto, o CNM resultou em menor intervalo do início da reprodução à concepção (IRC de 30,5 dias). Os manejos em campo nativo e em campo nativo com suplementação resultaram em intervalos reprodução-concepção de 36,4 e 39,4 dias, respectivamente. Os grupos de peso tiveram GMD semelhantes $(0,600 ; 0,612$ e $0,634 \mathrm{~kg} /$ dia) e mantiveram a diferença de peso vivo ao início dos manejos alimentares e ao início do período reprodutivo (299,6; 316,0 e 335,6 kg para leves, médias e pesadas, respectivamente). Nas novilhas pesadas, a taxa de prenhez foi maior (100\%) e o intervalo do início da reprodução à concepção (IRC), menor (29,86 dias). As novilhas leves tiveram taxa de prenhez de 91,6\% e o maior IRC (39,83 dias), cujas médias foram de 85,0\% e de 36,8 dias. Novilhas em melhor nível nutricional têm maior ganho de peso durante o inverno e maior peso ao início da reprodução. Novilhas mais velhas e mais pesadas concebem mais cedo e têm maior prenhez.

Palavras-chave: campo nativo melhorado, intervalo início da reprodução-concepção, prenhez, suplementação

\section{Influence of feeding management on weight gain and reproductive performance of beef heifers}

\begin{abstract}
The effects of three feeding management were evaluated in the winter months (CN: natural pasture; CNS: natural pasture + supplementation; CNM: improved natural pasture) and three live weight groups (light, medium, heavy) on the subsequent reproductive performance of Brangus heifers with first service to 24/27 mo old. Feeding managements showed differences in the daily weight gain (DWG) during the winter $(0.261,0.376$ and $0.679 \mathrm{~kg} / \mathrm{day})$ in body weight at the beginning of the reproductive period (302.8, 317.8 and $330.7 \mathrm{~kg}$ for CN, CNS and CNM, respectively). The pregnancy rate (PR) did not differ among the feeding managements (88.3, 93.3 and 95.0\% for CN, CNS, CNM, respectively). However, CNM has resulted in lower reproduction to conception interval (IRC of 30.5 days). The feeding managements on CN and CNS resulted in reproduction to conception interval of 36.4 and 39.4 days, respectively. Live weight groups showed similar DWG (0.600, 0.612 and $0.634 \mathrm{~kg} / \mathrm{day}$ ) and kept the difference in body weight at the beginning of feeding managements and at beginning of the reproductive period (299.6, 316.0 and $335.6 \mathrm{~kg}$ for light, medium and heavy groups, respectively). Among heifers of heavy group, the pregnancy rate was higher (100\%) and the time between the beginning of the reproduction - conception period (IRC), smaller (29.86 days). Light group heifers showed pregnancy rate of $91.6 \%$ and higher IRC (39.83 days), and heifers of the medium group $85.0 \%$ and 36.8 days, respectively.
\end{abstract}

Key Words: beginning of reproduction-conception interval, improved natural pasture, pregnancy, supplementation

\section{Introdução}

A exploração dos rebanhos de cria no Rio Grande do Sul caracteriza-se, historicamente, por ser realizada em campos nativos, sobre imensa diversidade de solos (Streck et al.,
2002), com ciclos médios e longos, associados a baixo custo operacional. Práticas de manejo tradicionais ou inapropriadas, como o excesso de carga animal (Fagundes et al., 2003), e a ausência de manejos específicos para determinadas categorias animais têm conduzido a indica- 
dores de baixa produtividade. No entanto, existem possibilidades de redução da idade de abate e da idade ao primeiro serviço, que podem permitir o aumento dos índices produtivos e reprodutivos (Pötter et al., 2000; Beretta et al., 2002; Fagundes et al., 2003).

Trabalhos com base em indicadores técnicos comprovam que qualquer mudança tecnológica na pecuária de corte deve ser feita com aumento na taxa de natalidade. Resultados indicam que a redução da idade ao primeiro serviço de novilhas para 2 anos de idade e o aumento da taxa de natalidade para índices superiores a 75\% determinam maior impacto na rentabilidade do sistema de produção em comparação à redução da idade de abate de novilhos dos 4,5 para 2,5 anos de idade (Grawunder \& Mielitz Netto, 1979; Beretta et al., 2002).

Para melhorar a eficiência biológica do rebanho, é necessário que a novilha atinja a puberdade e o acasalamento o mais cedo possível. Essas características adquirem maior importância à medida que o sistema de produção se torna mais intensivo e competitivo. A redução da idade de acasalamento de fêmeas altera a estrutura do rebanho de cria, reduzindo o intervalo entre gerações e diminuindo a participação de animais improdutivos na composição do rebanho (Pötter et al., 1998; Beretta et al., 2001).

Alternativas para assegurar adequada taxa de crescimento e sucesso reprodutivo são a utilização de pastagens cultivadas ou melhoradas, a suplementação energética e/ou protéica e o adequado manejo do campo nativo, ajustando e respeitando sua curva de produção às exigências do rebanho (Lobato, 2003). Desse modo, é fundamental estabelecer princípios de manejo e produção, inseridos na realidade do ambiente, com viabilidade técnica/ econômica, para ser possível aumentar de forma significativa o desempenho da pecuária regional e, do mesmo modo, da pecuária nacional.

Este trabalho foi conduzido com o objetivo de avaliar alternativas de manejo alimentar para desempenho produtivo e reprodutivo de novilhas de corte.

\section{Material e Métodos}

O experimento foi realizado na Estância São Pedro, propriedade da GAP-Genética Agropecuária, localizada no município de Uruguaiana, distrito do Ibirocai, região geográfica denominada Fronteira Oeste do Estado do Rio Grande do Sul, no período de 11/6/2004 a 28/1/2005.

Foram utilizadas 180 novilhas Brangus com 21 meses de idade, duplamente identificadas por meio de tatuagem na orelha e brincos numerados, distribuídas aleatoriamente nos tratamentos:
CN - 60 novilhas Brangus mantidas em campo nativo com carga animal de 0,6 UA/ha (270 kg de peso vivo por hectare), em que 1 unidade animal (UA) corresponde a $450 \mathrm{~kg} / \mathrm{PV}$;

CNS - 60 novilhas Brangus mantidas em campo nativo com carga animal de $0,6 \mathrm{UA} / \mathrm{ha}$, com suplementação de farelo de arroz integral + 2 \% de calcário calcítico na proporção de $1 \%$ do peso vivo/dia. Previamente à data de início do experimento, os animais foram mantidos em adaptação durante um período de 12 dias, no qual a quantidade diária de suplemento disponível foi aumentada gradativamente até atingir 1\% do peso vivo. O suplemento foi fornecido diariamente às 14 horas, em quantidade ajustada a cada 28 dias, de acordo com o peso dos animais. $\mathrm{O}$ farelo de arroz utilizado tinha $16,17 \%$ de proteína bruta (PB), 33,71\% de fibra em detergente neutro (FDN) e 11,44\% de extrato etéreo (EE). As duas áreas experimentais de campo nativo (CN e CNS), similares, constituintes de mesmo piquete, foram previamente pastejadas para uniformizar o nível de oferta de matéria seca depois de diferidas por 30 dias antes da entrada dos animais. Durante o período de 11/6/2004 a 10/9/2004, o manejo destas áreas foi realizado de forma alternada, a cada sete dias, com a finalidade de reduzir qualquer diferença ainda existente na oferta de forragem; e

CNM - 60 novilhas Brangus mantidas em campo nativo melhorado com carga animal de 0,6 UA/ha. Antes do início do trabalho, no mês de março, quando as espécies nativas eram predominantes na composição botânica da pastagem, foram introduzidas as espécies de ciclo hiberno-primaveril azevém (Lolium multiflorum Lam), trevo-branco (Trifolium repens) e cornichão (Lotus corniculatus cv. São Gabriel).

No início do trabalho, as novilhas foram estratificadas por peso (leves $=220$ a $240 \mathrm{~kg}$; médias $=240$ a $260 \mathrm{~kg}$; pesadas = 260 a $280 \mathrm{~kg}$ ) e distribuídas, aleatoriamente, nos três manejos alimentares.

A partir do dia 10/9/2004, as 180 novilhas foram manejadas em campo nativo, em um único grupo, com uma carga animal de $320 \mathrm{~kg}$ de peso vivo/ha. A inseminação artificial foi iniciada no dia 27/10/2004 e se estendeu por 45 dias, com repasse de touros na proporção de $2 \%$ até 28/1/2005, totalizando 93 dias de período reprodutivo. O diagnóstico de gestação das novilhas foi realizado no dia 1/4/2005, por meio de palpação retal, 60 dias após a estação de acasalamento.

A partir do início do experimento, todos os animais foram pesados, regularmente, com jejum prévio de sólidos e líquido de no mínimo 12 horas. O ganho médio diário (GMD) foi calculado considerando o intervalo das duas pesagens. Concomitante à pesagem, foi avaliada a condição corporal (CC) dos animais por meio de inspeção visual 
subjetiva, segundo a escala de 1 a 5, desenvolvida por Lowman et al. (1976), baseada na deposição de gordura corporal, em que 1 = magra e 5 = gorda .

A cada período de avaliação foram realizadas estimativas da massa média de forragem disponível de cada potreiro experimental utilizando-se o Método Comparativo de Haydock \& Shaw (1975). Amostras foram pesadas, acondicionadas em sacos de papel (identificados de acordo com o potreiro e a data de coleta) e secas em estufa de ventilação $\left(60^{\circ} \mathrm{C}\right)$ por 72 horas. Em subamostras parcialmente secas foram determinados os teores de proteína bruta (PB) e fibra em detergente neutro (FDN), conforme descrito pela AOAC (1984).

O experimento foi analisado segundo um delineamento completamente casualizado, com arranjo fatorial $3 \times 3$, composto de três sistemas de alimentação (campo nativo; campo nativo + suplementação; campo nativo melhorado) e três grupos de peso (leve, médio e pesado). Os dados foram submetidos à análise de variância e comparação múltipla de médias pelo teste de Tukey utilizando-se o programa estatístico SAS (1990), versão 6.08. As variáveis de resposta contínua, com distribuição normal, foram analisadas considerando número desigual de repetições.

Os efeitos dos manejos alimentares sobre a taxa de prenhez foram analisados pelo teste qui-quadrado (Steel \& Torrie, 1989). A data de concepção para cada novilha foi estimada considerando a data do parto e subtraindo-se 283 dias, correspondentes ao tempo de gestação médio da raça Brangus (Sawyer et al., 1991).

As características peso vivo inicial (PI) e final (PF), condição corporal inicial (CCI) e final (CCF), ganho médio diário, idade ao início do acasalamento (IIA) e intervalo reprodução-concepção (IRC) das novilhas foram analisadas segundo o modelo matemático a seguir:

$$
\mathrm{Y}_{\mathrm{ijk}}=\mathrm{u}+\mathrm{T}_{\mathrm{i}}+\mathrm{P}_{\mathrm{j}}+\mathrm{TP}_{\mathrm{ij}}+\mathrm{e}_{\mathrm{ijk}} ; \mathrm{i}=1,2,3 ; \mathrm{j}=1,2,3 .
$$
em que $Y_{\mathrm{ijk}}=$ PI, PF, CCI, CCF, GMD, IIA ou IRC da k-ésima novilha, pertencentes ao i-ésimo tratamento e ao j-ésimo grupo de peso; $\mathrm{u}=$ média geral; $\mathrm{T}_{\mathrm{i}}=$ efeito do tratamento $\mathrm{i}$; $\mathrm{P}_{\mathrm{j}}=$ efeito do grupo de peso $\mathrm{j}$; $\mathrm{TP}_{\mathrm{ij}}=$ efeito da interação do i-ésimo tratamento e j-ésimo grupo de peso; $\mathrm{e}_{\mathrm{ijk}}=$ efeito do erro aleatório associado a cada observação $\mathrm{Y}_{\mathrm{ijk}}$.

\section{Resultados e Discussão}

As novilhas mantidas em campo nativo, campo nativo + suplementação e campo nativo melhorado pesavam ao início do experimento 251,1; 251,2 e 252,2 kg e apresentavam condição corporal de 3,22; 3,12 e 3,20 (P>0,05). A análise de variância comprovou efeito significativo $(\mathrm{P}<0,05)$ dos manejos alimentares $(\mathrm{P}<0,05)$ no peso vivo e na condição corporal ao final do período de inverno. As novilhas mantidas em campo nativo melhorado com 313,2 kg foram mais pesadas que aquelas mantidas em campo nativo + suplementação $(284,9 \mathrm{~kg})$, que foram mais pesadas que as mantidas em campo nativo, 274,6 kg ( $\mathrm{P}<0,05$; Tabela 1).

Os ganhos médios diários de 0,261; 0,376; e 0,679 $(\mathrm{P}<0,05)$ obtidos em campo nativo, campo nativo + suplementação e campo nativo melhorado, respectivamente, resultaram em aumento de 0,78 ponto na condição corporal dos animais do campo nativo melhorado, que alcançaram condição corporal de 3,98 pontos ao final do período $(\mathrm{P}<0,05)$. Nos demais manejos alimentares (campo nativo e campo nativo + suplementação), os ganhos médios diários determinaram crescimento, mas esse crescimento foi insuficiente para evitar a perda de massa corpórea $(-0,20$ e $-0,12$, respectivamente) e não diferiram entre si $(\mathrm{P}>0,05)$; foram suficientes apenas para assegurar leve perda da condição corporal inicial (3,02 e 3,00).

O campo nativo melhorado, ao longo do período, apresentou massa média de forragem de $1.345 \mathrm{~kg} / \mathrm{MS} / \mathrm{ha}$ com 10,91\% de proteína bruta e 74,84\% de fibra em detergente neutro.

Os resultados encontrados na literatura para ganho de peso de novilhas de sobreano em campo nativo melhorado, são bastante variáveis, influenciados principalmente por variações climáticas e pela composição botânica, que interfere na disponibilidade e qualidade da forragem, e pelo período de utilização da pastagem. Nardon et al. (1987)

Tabela 1 - Peso vivo, condição corporal e ganho médio diário em cada manejo alimentar

\begin{tabular}{lccc}
\hline Característica & \multicolumn{3}{c}{ Manejo alimentar } \\
\cline { 2 - 4 } & Campo nativo & Campo nativo + suplementação & Campo nativo melhorado \\
\hline Peso, kg (11/6/2004) & 251,1 & 251,2 & 252,1 \\
Condição corporal inicial & 3,22 & 3,12 & 3,20 \\
Peso, kg (10/9/2004) & $274,6 \mathrm{c}$ & $284,9 \mathrm{~b}$ & $313,2 \mathrm{a}$ \\
Condição corporal final & $3,02 \mathrm{~b}$ & $3,00 \mathrm{~b}$ & $3,98 \mathrm{a}$ \\
GMD (kg/dia) & $0,261 \mathrm{c}$ & $0,376 \mathrm{~b}$ & $0,679 \mathrm{a}$ \\
\hline
\end{tabular}

Médias na mesma linha seguidas de letras diferentes diferem $(P<0,05)$ entre si pelo teste Tukey. 
verificaram ganho médio diário de 0,460 kg durante o segundo inverno/primavera pós-desmama de novilhas cruzas Charolês. Beretta \& Lobato (1996), avaliando o efeito da ordem de utilização de pastagens melhoradas (ponta e rapador) no desempenho de novilhas de sobreano, observaram maior ( $<<0,01)$ ganho médio diário $(0,904 \mathrm{~kg})$ para as novilhas do grupo "ponta” em comparação àquelas do grupo "rapador" (0,600 kg). Pereira Neto \& Lobato (1998), utilizando o mesmo sistema de pastejo, verificaram ganho médio diário de 0,674 kg para o sistema "ponta" e 0,582 kg para o sistema "rapador" $(\mathrm{P}<0,01)$. Albospino \& Lobato (1993), em pesquisa com novilhas cruzas Red Angus $\times$ Nelore $\times$ Charolês no segundo inverno/primavera pós-desmama, determinaram durante os primeiros 44 dias de pastejo ganho médio diário de 0,485 kg. Depois que os animais permanecerem 60 dias em campo nativo e retornarem à pastagem melhorada para um segundo período de 55 dias, os autores determinaram ganho médio diário de 1,021 kg/dia.

Neste trabalho, a carga de 0,6 UA/ha no campo nativo possibilitou ganho médio diário de 0,261 kg. Com cargas moderadas, Berrutti et al. (1993) observaram ganho médio diário de 0,260 kg em novilhas ao primeiro serviço aos 2 anos de idade em campo nativo.

A massa média de forragem disponível no campo nativo durante os três períodos de avaliação foi de 2.505; 2.087 e $1.515 \mathrm{~kg} / \mathrm{MS} / \mathrm{ha}$ com 7,45\% de PB e 80,49\% de FDN. A análise bromatológica comprovou teor de PB compatível com o descrito por Van Soest (1994) como mínimo adequado para manutenção da flora microbiana (7\%).

A possível explicação para o ganho médio diário de 0,261 kg em campo nativo, além da oferta bastante satisfatória, é que as amostras utilizadas na análise qualitativa foram as mesmas usadas como padrão da amostragem da determinação da massa média em cada potreiro experimental. Portanto, não estão, necessariamente, associadas à forragem selecionada e realmente consumida pelos animais (Gibb \& Treacher, 1976).

Apesar do período de 12 dias de adaptação das novilhas do campo nativo + suplementação, durante os primeiros 30 dias de fornecimento do suplemento (11/6/2004 a 8/7/2004), o desempenho não correspondeu ao aporte nutricional oferecido e resultou em ganho médio diário de $0,161 \mathrm{~kg}$, menor que o de $0,189 \mathrm{~kg}$ obtido em campo nativo.

O menor desempenho dos animais no início da suplementação pode estar associado à proporção do suplemento ofertada diariamente, ao teor de gordura, à digestibilidade da fibra e, ainda, ao possível efeito associativo negativo entre concentrado e volumoso (Rocha, 1999). Possivelmente, teria sido necessário mais tempo para adaptação à quantidade e às características do suplemento, o que não possibilitou efeito aditivo sobre o desempenho animal no período inicial, ocorrendo diferença significativa $(\mathrm{P}<0,05)$ no ganho médio diário somente nas avaliações subseqüentes.

Ospesos iniciais (Tabela 2) foram de 232,9; 250,8 e 270,6 kg para novilhas leves, médias e pesadas $(\mathrm{P}<0,05)$, respectivamente. Ao final do período, as novilhas leves pesavam em média 272,5 kg, as médias 289,9 kg e as pesadas 310,3 kg $(\mathrm{P}<0,05)$, portanto, a diferença de peso inicial entre novilhas leves, médias e pesadas manteve-se durante o período de 11/6/2004 a 10/9/2004, pois em todas as avaliações houve diferença significativa $(\mathrm{P}<0,05)$ entre os grupos de peso.

Os ganhos médios diários foram semelhantes $(\mathrm{P}>0,05)$ entre as novilhas leves, médias e pesadas, 0,600; 0,612; $0,634 \mathrm{~kg} / \mathrm{dia}$, respectivamente. Entre os grupos de peso, a condição corporal final não diferiu $(\mathrm{P}>0,05)(3,37 ; 3,33$ e 3,32 ). No entanto, as novilhas leves apresentaram ganho de condição corporal de $0,25(\mathrm{P}<0,05)$ e não diferiram daquelas de peso médio ( 0,18 ponto), que não diferiram das novilhas classificadas como pesadas, que tiveram menor ganho de condição corporal (0,06 ponto).

Os resultados indicaram ganho médio diário semelhante $(0,600 \mathrm{~kg} / \mathrm{dia})$. O ganho de condição corporal dos animais de menor peso foi semelhante ao dos animais médios $(\mathrm{P}>0,05)$ e superior ao dos animais pesados $(\mathrm{P}<0,05)$. Beretta \& Lobato (1996) também não verificaram diferenças $(\mathrm{P}>0,05)$ no ganho de peso de novilhas de sobreano manejadas em pastagem melhorada, estratificadas em leves e pesadas (0,732 e 0,772 kg/dia, respectivamente).

Pereira Neto \& Lobato (1998), em estudo sobre recria de bezerras, distribuíram os animais em três grupos de peso e dois fenótipos (Bos taurus e Bos indicus) e observaram que as diferenças de peso se mantiveram no decorrer do primeiro inverno $(\mathrm{P}<0,01)$, de modo que o grupo de maior peso inicial apresentou peso médio superior $(188,4 \mathrm{~kg})$ ao intermediário (169,7 kg) e ao leve (148,7 kg). No segundo

Tabela 2 - Peso vivo (kg), condição corporal (CC), ganho de condição corporal (GCC) e ganho médio diário (GMD) de novilhas de corte de três grupos de peso

\begin{tabular}{lccc}
\hline Característica & \multicolumn{3}{c}{ Grupo de peso } \\
\cline { 2 - 4 } & Leve & Média & Pesada \\
\hline Peso, kg (11/6/2004) & $232,9 \mathrm{c}$ & $250,8 \mathrm{~b}$ & $270,6 \mathrm{a}$ \\
Condição corporal inicial & $3,12 \mathrm{~b}$ & $3,15 \mathrm{ab}$ & $3,26 \mathrm{a}$ \\
Peso, kg (10/9/2004) & $272,5 \mathrm{c}$ & $289,9 \mathrm{~b}$ & $310,3 \mathrm{a}$ \\
Condição corporal final & 3,37 & 3,33 & 3,32 \\
Ganho de condição & $0,25 \mathrm{a}$ & $0,18 \mathrm{ab}$ & $0,06 \mathrm{~b}$ \\
corporal, pontos & & & \\
Ganho médio diário (kg/dia) & 0,600 & 0,612 & 0,634 \\
\hline
\end{tabular}

Médias na mesma linha seguidas de letras diferentes diferem $(P<0,05)$ entre si pelo teste Tukey. 
inverno, as diferenças de peso persistiram, mas, ao final desse período, apenas o grupo de maior peso diferiu dos demais $(\mathrm{P}<0,01)$. Os ganhos médios diários dos grupos de peso não diferiram $(\mathrm{P}>0,05)$ durante o segundo inverno $(0,607 ; 0,654 ; 0,630 \mathrm{~kg}$, respectivamente), indicando que, independentemente do peso inicial, os animais apresentaram desempenhos individuais semelhantes até o segundo ano em pastagem nativa melhorada. Os resultados comprovaram que o sistema de pastejo e a forragem utilizada durante o período hibernal mantiveram as diferenças de peso vivo entre os grupos, mas os animais de menor peso vivo tenderam a depositar maior quantidade de gordura.

Os pesos médios ao início do acasalamento (Tabela 3) foram de 302,8; 317,8 e 330,7 kg para as novilhas em campo nativo, campo nativo + suplementação e campo nativo melhorado, que diferiram entre si $(\mathrm{P}<0,05)$. Segundo o NRC (1996), o peso a ser atingido no início da estação de acasalamento para Bos taurus é de $60 \%$ do peso à idade adulta. Considerando esse parâmetro estabelecido pelo NRC e o peso adulto do rebanho em estudo (470 kg), os manejos alimentares e os grupos de peso vivo tiveram pesos médios suficientes ao início do acasalamento para bons resultados reprodutivos.

Segundo Rovira (1996), os pesos de 280 a $300 \mathrm{~kg}$ de raças britânicas e suas cruzas ao início do período reprodutivo são suficientes para o mínimo de 85\% de prenhez nas primeiras seis semanas. Nardon et al. (1987) constataram em novilhas mestiças Charolês pesos médios de 270,8 kg ao início do acasalamento aos 24/27 meses de idade manejadas durante dois invernos/primaveras pós-desmama em campo nativo melhorado.

Em trabalhos com melhor nível nutricional, pesquisadores observaram pesos vivos semelhantes ao deste experimento. Pio de Almeida \& Lobato (2004), com o objetivo de avaliar o efeito de duas idades de desmame (90 ou 170 dias) e suplementação durante o primeiro inverno pós-desmame, verificaram pesos ao início do acasalamento aos $24 / 26$ meses de 323,7 e $327,1 \mathrm{~kg}$, respec- tivamente, para os desmames aos 90 e aos 170 dias $(\mathrm{P}>0,05)$. Albospino \& Lobato (1993) observaram pesos ao início do acasalamento de 348 e $345 \mathrm{~kg}$ para novilhas Red Angus $\times$ Nelore $\times$ Charolês desmamadas aos 100 e 150 dias e mantidas durante dois invernos/primaveras pós-desmame em pastagem melhorada.

Beretta \& Lobato (1996) obtiveram pesos ao início do acasalamento de 351,7 e 298,6 kg ( $\mathrm{P}<0,01)$ em experimento no qual testaram o sistema "ponta e rapador" em pastagem melhorada durante o primeiro e segundo inverno/primavera pós-desmame. Pereira Neto \& Lobato (1998) verificaram pesos de 324,9 e $297,0(\mathrm{P}<0,01)$ para os lotes "ponta e rapador”, respectivamente.

A análise de variância indicou diferença $(P<0,01)$ no ganho médio diário durante o período de acasalamento: ganhos de 0,566; 0,494 e 0,432 kg/dia nos manejos em campo nativo, campo nativo + suplementação e campo nativo melhorado, portanto, a diferença $(\mathrm{P}<0,05)$ nos pesos manteve-se até o final da estação reprodutiva (353,7; 362,2 e $369,6 \mathrm{~kg}$, respectivamente). Apesar da manutenção da diferença estatística entre os pesos vivos ao final do período reprodutivo, essa diferença diminuiu entre os manejos alimentares.

Os ganhos médios diários obtidos durante o período reprodutivo podem ser considerados satisfatórios se considerada a deficiência hídrica entre os meses de dezembro de 2004 e março de 2005 (média de 22 mm), que influenciou significativamente a taxa de crescimento nas pastagens nativas. Embora a oferta forrageira média de $1.320 \mathrm{~kg} / \mathrm{MS} / \mathrm{ha}$ tenha sido baixa para a carga animal de $320 \mathrm{~kg} / \mathrm{ha}$, a forragem apresentou 9,09\% de PB e 75,42\% de FDN. Os ganhos médios diários foram superiores ao de 0,209 kg/dia observado por Albospino \& Lobato (1993) e ao de $0,138 \mathrm{~kg} /$ dia descrito por Pio de Almeida \& Lobato (2004), porém, foram próximos ao de $0,377 \mathrm{~kg} /$ dia verificado por Pereira Neto \& Lobato (1998).

O maior ganho médio diário obtido nos manejos em campo nativo e campo nativo + suplementação pressupõe

Tabela 3 - Desempenho de novilhas no período reprodutivo submetidas previamente a diversos manejos alimentares

\begin{tabular}{|c|c|c|c|c|}
\hline & \multicolumn{4}{|c|}{ Manejo alimentar } \\
\hline & Campo nativo & Campo & nativo + suplementação & Campo nativo melhorado \\
\hline Peso inicial (kg) & $302,8 c$ & & $317,8 b$ & $330,7 \mathrm{a}$ \\
\hline Condição corporal inicial & 3,28 & & 3,24 & 3,26 \\
\hline Peso final (kg) & $353,7 c$ & & $362,2 b$ & $369,6 a$ \\
\hline Condição corporal final & $3,60 \mathrm{a}$ & & $3,53 b$ & $3,52 b$ \\
\hline Ganho diário do início à metade (kg/dia) & $0,522 \mathrm{a}$ & & $0,455 \mathrm{a}$ & $0,377 b$ \\
\hline Ganho diário da metade ao final (kg/dia) & $0,609 a$ & & $0,531 b$ & $0,487 \mathrm{~b}$ \\
\hline Ganho médio diário do período reprodutivo (kg/dia) & $0,566 a$ & & $0,494 b$ & $0,432 \mathrm{c}$ \\
\hline
\end{tabular}

Médias na mesma linha seguidas de letras diferentes diferem $(P<0,05)$ pelo teste Tukey. 
a ocorrência de ganhos compensatórios no período reprodutivo. O’Donovan (1984) e Ryan (1990) revisaram diversos trabalhos sobre ganho compensatório de ruminantes após períodos de restrição alimentar e constataram que a resposta animal em recuperação total ou parcial depende da idade em que ocorreu a restrição, da severidade da restrição e do nível e da qualidade do alimento utilizado no período de realimentação.

Pereira Neto \& Lobato (1998) observaram que os animais no sistema rapador durante o período de pastejo conjunto em campo nativo de novembro a junho apresentaram ganho de peso superior ao obtido no lote ponta $(0,272$ vs $0,220 \mathrm{~kg} / \mathrm{dia})$, o que ocorreu também no período seguinte em pastejo conjunto de novembro a janeiro $(0,430$ vs 0,320 kg/dia), indicando a existência de ganhos compensatórios, conforme proposto por Ryan (1990).

Ao final dos manejos alimentares em 10/9/2004 (Tabela 1), a condição corporal dos animais em campo nativo melhorado $(3,98)$ diferiu $(\mathrm{P}<0,05)$ da observada em campo nativo $(3,02)$ e em campo nativo + suplementação $(3,0)$. A partir desse período, os animais passaram a ser manejados conjuntamente em campo nativo e apresentaram ganho médio diário de 0,598; 0,699 e 0,373 kg/dia. Ao início do período reprodutivo, em 27/10/2004, a diferença na condição corporal dos animais deixou de existir $(\mathrm{P}>0,05) \mathrm{e}$ valores de 3,28; 3,24 e 3,26 foram obtidos para campo nativo, campo nativo + suplementação e campo nativo melhorado, respectivamente.

Os ganhos médios diários obtidos durante o período reprodutivo conferiram maior deposição de gordura às novilhas em campo nativo, que apresentaram condição corporal ao final do acasalamento superior $(\mathrm{P}<0,05), 3,60$ pontos, à observada nos demais manejos alimentares. Os manejos em campo nativo + suplementação e campo nativo melhorado não diferiram $(\mathrm{P}>0,05)$ quanto à condição corporal ao final do período reprodutivo, que foi de 3,53 e 3,52, respectivamente.

O menor ganho médio diário e a perda de condição corporal do tratamento campo nativo melhorado durante o manejo conjunto em campo nativo em comparação aos manejos em campo nativo e campo nativo + suplementação podem ser explicados pelo efeito adaptativo ao novo ambiente. A menor adaptação da flora microbiana é uma das possíveis causas do menor desempenho dos animais quando retirados da pastagem melhorada e submetidos a novo manejo alimentar, pois levam algum tempo para se adequarem à nova dieta (Ferrell, 1982).

Rocha et al. (2004) avaliaram o desenvolvimento de novilhas de corte em pastagem de aveia-preta e azevém, com e sem suplementação energética, e também verificaram perda de peso (-0,185 kg/dia) das novilhas quando retiradas da pastagem e manejadas em campo nativo a partir do início da primavera. Os autores comentaram que esse problema deve ser bem compreendido e considerado, pois fornecer melhor aporte nutricional para novilhas de reposição envolve custos adicionais significativos ao sistema de produção, portanto, pode não ser bioeconomicamente conveniente, uma vez que os aumentos em ganho de peso e condição corporal são desperdiçados no período subseqüente.

Em todos os manejos alimentares empregados, as novilhas apresentaram ao início da época de reprodução peso e condição corporal adequados, o que permitiu condições suficientes para bons índices reprodutivos. Além disso, ao longo do período reprodutivo, os animais apresentaram ganho de peso significativo $(\mathrm{P}<0,05)$ e constante, em média, de 0,451 kg/dia nos primeiros 46 dias e $0,542 \mathrm{~kg} / \mathrm{dia}$ nos 47 dias subseqüentes (Tabela 3).

O peso ao início da reprodução diferiu $(\mathrm{P}<0,05)$ entre os grupos, com 299,6 kg no grupo leve, 316,0 kg no grupo médio e 335,6 kg no grupo pesado. Entre os grupos de peso, o ganho médio diário das novilhas pesadas foi de $0,514 \mathrm{~kg}$ enão diferiu $(\mathrm{P}>0,05)$ do observado no grupo médio $(0,498 \mathrm{~kg})$, que não diferiu daquele obtido no grupo leve $(0,479 \mathrm{~kg})$. As diferenças de peso entre os grupos $(\mathrm{P}<0,05)$ mantiveram-se ao final da estação reprodutiva: 342,7; 360,9 e 382,0 kg para novilhas leves, médias e pesadas, respectivamente. Não foi observada diferença $(\mathrm{P}>0,05)$ na condição corporal ao início e final do acasalamento entre os grupos de peso. As médias das condições corporais ao início da reprodução foram de 3,25; 3,28 e 3,24 e, ao final, de 3,54; 3,56 e 3,55 para leves, médias e pesadas, respectivamente (Tabela 4).

Pereira Neto \& Lobato (1998) verificaram diferenças $(\mathrm{P}<0,01)$ de pesos vivos ao início da reprodução do grupo de novilhas pesadas em relação aos grupos de novilhas leves e intermediárias, que não diferiram $(\mathrm{P}>0,05)$ entre si. O grupo de animais leves apresentou peso médio de $289,5 \mathrm{~kg}$, o grupo

Tabela 4 - Peso médio $(\mathrm{kg})$ e condição corporal de novilhas de três grupos de peso ao início e ao final do acasalamento e ganho médio diário (GMD)

\begin{tabular}{lccc}
\hline Característica & \multicolumn{3}{c}{ Grupo de peso } \\
\cline { 2 - 4 } & Leve & Média & Pesada \\
\hline Peso médio inicial & $299,6 \mathrm{c}$ & $316,0 \mathrm{~b}$ & $335,6 \mathrm{a}$ \\
Condição corporal inicial & 3,25 & 3,28 & 3,24 \\
Peso médio final & $342,7 \mathrm{c}$ & $360,9 \mathrm{~b}$ & $382,0 \mathrm{a}$ \\
Condição corporal final & 3,54 & 3,56 & 3,55 \\
Ganho médio diário (kg/dia) & $0,479 \mathrm{~b}$ & $0,498 \mathrm{ab}$ & $0,514 \mathrm{a}$ \\
\hline
\end{tabular}

Médias na mesma linha seguidas de letras diferentes diferem $(P<0,05)$ pelo teste Tukey. 
de peso intermédio 312,9 kg e o grupo dos animais pesados 333,7 kg. Beretta \& Lobato (1996), com novilhas ao início da reprodução aos 24/26 meses de idade, ao estratificarem em grupos de peso leves e pesadas, constataram pesos médios de 308 e $343 \mathrm{~kg}$, respectivamente $(\mathrm{P}<0,01)$.

As taxas de prenhez de 88,3; 93,3 e 95\% não diferiram $(\mathrm{P}>0,05)$ entre os manejos alimentares em campo nativo, campo nativo + suplementação e campo nativo melhorado (Tabela 5).

Del Duca \& Lopez (1980), com o objetivo de avaliar o efeito da suplementação em campo nativo no desempenho produtivo e reprodutivo de novilhas Brangus, constataram peso médio ao início do acasalamento de 278 kg e índice de prenhez de $87,5 \%$.

Pio de Almeida \& Lobato (2004) verificaram índices de prenhez de 77,3 e 72,0\% para novilhas desmamadas precocemente aos 90 dias ou em idade convencional, aos 170 dias, respectivamente $(\mathrm{P}>0,05)$. Nardon et al. (1987) em dois lotes de novilhas pesando em média 280 e 270,8 kg ao início da estação reprodutiva, observaram índices de prenhez de 62 e 58,5\%, respectivamente. Albospino \& Lobato (1993) constataram pesos médios ao início do período de acasalamento de 331 e 325 kg e obtiveram índices de prenhez de 71 e 75\% $(\mathrm{P}>0,05)$, respectivamente. Nestes trabalhos, os autores questionaram a possibilidade da existência de subfertilidade no rebanho.

Os índices de prenhez verificados neste trabalho podem ser considerados elevados se comparados às médias nacional e regional e estão relacionados à genética do rebanho, ao adequado crescimento, ao peso e à condição corporal ao início do período reprodutivo, associados ao nível sanitário empregado, um somatório de condições que permite bons resultados em qualquer manejo imposto.

A taxa de prenhez diferiu $(\mathrm{P}<0,01)$ entre os grupos de peso. As novilhas pesadas apresentaram taxa de prenhez de $100 \%$ e diferindo das leves (91,6\%) e das médias (85\%), que não diferiram entre si (Tabela 6). Estes resultados comprovam a influência do peso vivo na concepção das novilhas, uma vez

Tabela 5 - Taxa de prenhez (\%) das novilhas em cada manejo alimentar

\begin{tabular}{lccc}
\hline Manejo alimentar & Prenhes & Não-prenhes & $\begin{array}{c}\text { Taxa de } \\
\text { prenhez }\end{array}$ \\
\hline Campo nativo & 53 & 7 & 88,3 \\
Campo nativo + & 56 & 4 & 93,3 \\
$\begin{array}{l}\text { suplementação } \\
\text { Campo nativo melhorado }\end{array}$ & 57 & 3 & 95,0 \\
\hline
\end{tabular}

Médias na mesma coluna seguidas de letras diferentes diferem $(P<0,05)$ pelo teste qui-quadrado. que os animais pesados apresentaram índice de prenhez superior ao obtido com os animais de menor peso vivo.

No experimento conduzido por Beretta \& Lobato (1996), a taxa de prenhez das novilhas do sistema ponta foi maior que a obtida no sistema rapador $(100 \% \times 71 \%$; $<<0,01)$, portanto, não houve diferenças $(\mathrm{P}>0,05)$ entre os grupos de peso leves $(80,6 \%)$ e pesadas (90\%). No entanto, o desempenho reprodutivo das novilhas esteve relacionado à interação grupo $\times$ tratamento $(P<0,01)$, uma vez que as novilhas mais leves apresentaram menor taxa de prenhez. No grupo de animais leves, as novilhas do sistema "rapador" apresentaram desempenho reprodutivo menor $(\mathrm{P}<0,01)$ que o daquelas do sistema "ponta" $(62,5 \times 100 \%)$, que não diferiu $(\mathrm{P}>0,05)$ entre as novilhas pesadas $(80 \times 100 \%)$.

Pereira Neto \& Lobato (1998), avaliando os grupos de peso, apesar de identificarem diferença estatística no peso ao início do acasalamento favorável ao grupo pesado sobre os grupos leve e intermediário, não constataram diferenças $(\mathrm{P}>0,05)$ entre as taxas de prenhez $(90,0 ; 83,3$ e 83,3\%, respectivamente).

A média de idade ao início do acasalamento diferiu entre os grupos de peso. As novilhas mais pesadas eram mais velhas (778 dias), as de menor peso as mais jovens (762 dias) e as de peso médio tinham idade intermediária (770 dias), não diferindo das novilhas dos grupos leve e pesado $(\mathrm{P}>0,05)$. Vieira et al. (2006), em pesquisa com novilhas Nelore, observaram maior taxa de prenhez em novilhas mais velhas ao início da reprodução: 59,4 e 86,2\% para novilhas com 715 e 760 dias, respectivamente. Esses autores determinaram efeito significativo entre os anos e o peso das novilhas.

Os grupos de peso comprovaram influência significativa dos manejos alimentares em campo nativo e campo nativo melhorado, mas nenhum efeito $(\mathrm{P}>0,05)$ do manejo em campo nativo + suplementação (Tabela 7).

No manejo em campo nativo, as taxas de prenhez não diferiram $(\mathrm{P}>0,01)$ entre as novilhas pesadas e leves, cujos índices foram de 100 e $95 \%$, respectivamente. Houve diferença $(\mathrm{P}<0,05)$, no entanto, para as novilhas médias, que apresentaram menor desempenho reprodutivo (70,0\%).

Tabela 6 - Taxa de prenhez e média de idade das novilhas em cada grupo de peso

\begin{tabular}{lcccc}
\hline Grupo de peso & Prenhes & Não-prenhes & $\begin{array}{c}\text { Idade } \\
\text { (dias)** }\end{array}$ & $\begin{array}{c}\text { Taxa de } \\
\text { prenhez* }\end{array}$ \\
\hline Leves & 55 & 5 & $762 \mathrm{~b}$ & $91,6 \mathrm{~b}$ \\
Médias & 51 & 9 & $770 \mathrm{ab}$ & $85,0 \mathrm{~b}$ \\
Pesadas & 60 & 0 & $778 \mathrm{a}$ & $100,0 \mathrm{a}$ \\
\hline
\end{tabular}

* Médias seguidas de letras distintas nas colunas diferem $(P<0,01)$ pelo teste qui-quadrado.

** Médias na mesma coluna seguidas de letras diferentes diferem $(P<0,05)$ pelo teste Tukey. 
Tabela 7 - Taxas de prenhez de novilhas de três grupos de peso em três manejos alimentares

\begin{tabular}{|c|c|c|c|c|c|c|c|c|c|}
\hline & \multicolumn{3}{|c|}{ Campo nativo } & \multicolumn{3}{|c|}{ Campo nativo + suplementação } & \multicolumn{3}{|c|}{ Campo nativo melhorado } \\
\hline & Leve & Média & Pesada & Leve & Média & Pesada & Leve & Média & Pesada \\
\hline Prenhes & 19 & 14 & 20 & 19 & 17 & 20 & 17 & 20 & 20 \\
\hline Taxa de prenhez & $95 a$ & $70 \mathrm{~b}$ & $100 \mathrm{a}$ & 95 & 85 & 100 & $85 b$ & $100 \mathrm{a}$ & $100 \mathrm{a}$ \\
\hline
\end{tabular}

Médias na mesma linha seguidas de letras diferentes diferem $(P<0,05)$ pelo teste qui-quadrado.

Os grupos pesado e médio no manejo em campo nativo melhorado apresentaram taxa de prenhez de $100 \%$ e diferiram estatisticamente das novilhas do grupo leve, cuja taxa de prenhez foi de $85 \%$. Byerley et al. (1987) afirmam que, quanto mais velhas as novilhas, em condições semelhantes de nutrição, maiores as chances de apresentarem ciclos antes do início da reprodução, o que pode aumentar significativamente a probabilidade de concepção, uma vez que os índices são superiores em novilhas que já expressaram, no mínimo três ciclos estrais antes estação reprodutiva.

A data média de concepção diferiu estatisticamente entre os grupos de peso e os manejos alimentares, o que comprova a influência desses fatores na velocidade de concepção das novilhas. O campo nativo melhorado resultou em menor intervalo reprodução-concepção (30,58 dias) e diferiu significativamente $(\mathrm{P}<0,05)$ dos demais manejos alimentares. Os manejos em campo nativo e campo nativo + suplementação resultaram em intervalos de 36,47 e 39,44 dias, respectivamente $(\mathrm{P}>0,05)$.

As novilhas do grupo pesado apresentaram o menor intervalo reprodução-concepção (29,86 dias), que diferiu $(\mathrm{P}<0,05)$ dos demais manejos alimentares. O grupo leve apresentou o maior intervalo (39,83 dias), embora não tenha diferido ( $\mathrm{P}>0,05)$ do grupo médio (36,8 dias). Vieira et al. (2006) determinaram efeito significativo entre os anos e o peso das novilhas; em 2000, as novilhas apresentaram o menor peso, o maior número de dias para parir e a menor taxa de prenhez.

Independentemente dos manejos alimentares e do grupo de peso, $52 \%$ das novilhas conceberam durante os primeiros 31 dias, $26 \%$ entre o 32 o e o 62 o dia do período reprodutivo e $23 \%$ a partir do $63^{\circ}$ dia. Beretta \& Lobato (1996) não verificaram diferença significativa na data média de concepção entre os manejos ponta e rapador, grupos de peso ou tipo racial $(\mathrm{P}>0,05)$. Esses sistemas de manejo resultaram em intervalos médios reprodução-concepção de 27,5 e $26,6 \pm 14,3$ dias.

\section{Conclusões}

Novilhas em campo nativo melhorado ou em campo nativo + suplementação apresentam maior taxa de ganho de peso durante o inverno e maior peso vivo ao início da reprodução em comparação às manejadas exclusivamente em campo nativo. Novilhas mantidas em campo nativo melhorado apresentam menor intervalo do início da reprodução à concepção. As novilhas mais velhas e mais pesadas foram superiores em índice de prenhez e velocidade de concepção em comparação às mais jovens e de menor peso.

\section{Literatura Citada}

ALBOSPINO, B.H.J.C.; LOBATO, J.F.P. Efeitos do desmame precoce de terneiras no desempenho até os 24-26 meses de idade. Revista da Sociedade Brasileira de Zootecnia, v.22, n.6, p.1033-1043, 1993.

ASSOCIATION OF OFFICIAL AGRICULTURAL CHEMISTS AOAC. Official methods of analysis of AOAC International. 16.ed. Washington, D.C.: 1984. 1141p.

BERETTA, V.; LOBATO, J.F.P. Efeitos da ordem de utilização de pastagens melhoradas no ganho de peso e comportamento reprodutivo de novilhas de corte. Revista da Sociedade Brasileira de Zootecnia, v.25, n.6, p.1196-1206, 1996.

BERETTA, V.; LOBATO, J.F.P.; MiELiTZ NETTO, C.G.A. Produtividade e eficiência biológica de sistemas pecuários de cria diferindo na idade das novilhas ao primeiro parto e na taxa de natalidade do rebanho no Rio Grande do Sul. Revista Brasileira de Zootecnia, v.29, n.4, p.1278-1286, 2001.

BERETTA,V.; LOBATO, J.F.P.; MIELITZ NETTO, C.G.A. Produtividade e eficiência biológica de sistemas de produção de gado de corte de ciclo completo no Rio Grande do Sul. Revista Brasileira de Zootecnia, v.31, n.2, p.991-1001, 2002 (supl.).

BERRUTTI, J.M.; JASO,M.; LÁZARO, B.D. Desarrollo tecnológico del estabelecimientos ganaderos. Boletim de divulgación n.36. Instituto Nacional de Investigación Agropecuaria. Montevideo: Hemisferio Sur, 1993. 38p.

BYERLEY, J.R.B.; STAIGMILLER, R.B.; BERARDINELLI, J.G. et al. Pregnancy rates of beef heifers bred either on pubertal or third estrus. Journal of Animal Science, v.65, n.3, p.645650, 1987.

DEL DUCA, L.O.A.; LOPEZ, J. Suplementação de novilhas em pastagem natural e seu efeito no peso ao acasalamento. Revista da Sociedade Brasileira de Zootecnia, v.9, n.1, p.19-30, 1980.

FAGUNDES, J.I.B.; LOBATO, J.F.P.; SCHENKEL, F.S. Efeito de duas cargas animais em campo nativo e duas idades à desmama no desempenho de vacas de corte primíparas. Revista Brasileira de Zootecnia, v.32, n.6, p.1722-1731, 2003.

FERRELL, C.L. Effects of postweanning rate of gain on onset of puberty and productive performance of heifers of different breeds. Journal of Animal Science, v.55, n.6, p.1272-1283, 1982.

GIBB, M.J.; TREACHER, T.T. The effect of herbage allowance on herbage intake and performance of lambs grazing perennial ryegrass and red clover swards. Journal of Agricultural Science, v.86, n.2, p.355-365, 1976. 
GRAWUNDER, A.; MIELITZ NETTO, C.G.A. Pecuária de corte no sul do Brasil. Revista de Economia Rural, v.17. p.119-136, 1979.

HAYDOCK, K.P.; SHAW, N.H. The comparative yield method for estimating dry matter yield of pasture. Australian Journal of Experimental Agriculture and Animal Husbandry, v.15, n.72, p.663-670, 1975.

LOBATO, J.F.P. A "vaca ideal" e seu manejo em sistemas de produção de ciclo curto. In:SIMPÓSIO DA CARNE BOVINA: DA TPODUÇÃO AO MERCADO CONSUMIDOR, 1., 2003, São Borja. Anais... Porto Alegre: Universidade Federal do Rio Grande do Sul, 2003. p.9-46.

LOWMAN, B.G.; SCOTT, N.; SOMERVILLE, S. Condition scoring beef cattle. Edinburgh: East of Scotland College of Agriculture, 1976. 8p. (Bulletin, 6).

NARDON, R.F.; LOBATO, J.F.P.; COELHO JR., W. Efeito das pastagens nativas e melhoradas no ganho de peso das terneiras desmamadas. Zootecnia, v.25, n.2, p.91-105, 1987.

NATIONAL RESEARCH COUNCIL - NRC. Nutrient requeriments of beef cattle. 6.ed. Washington, D.C.: National Academy Press, 1996. $187 p$.

O'DONOVAN, P.B. Compensatory gain in cattle and sheep. Nutrition Abstract Review, v.54, n.8, p.389-410, 1984.

PEREIRA NETO, O.A.; LOBATO, J.F.P. Efeitos da ordem de utilização de pastagens nativas melhoradas no desenvolvimento e comportamento reprodutivo de novilhas de corte. Revista Brasileira de Zootecnia, v.27, n.1, p.60-65, 1998.

PIO DE ALMEIDA, L.S.; LOBATO, J.F.P. Efeito da idade de desmame e suplementação no desenvolvimento de novilhas de corte. Revista Brasileira de Zootecnia, v.33, n.6, p.20862094, 2004

PÖTTER, L.; LOBATO, J.F.P.; MIELITZ NETTO, C.G.A. Produtividade de um modelo de produção para novilhas de corte primíparas aos dois, três e quatro anos de idade. Revista Brasileira de Zootecnia, v.27, n.3, p.613-619, 1998.
PÖTTER, L.; LOBATO, J.F.P.; MIELITZ NETTO, C.G.A. Análises econômicas de modelos de produção com novilhas de corte primíparas aos dois, três e quatro anos de idade. Revista Brasileira de Zootecnia, v.29, n.3, p.861-870, 2000.

ROCHA, M.G. Suplementação a campo de bovinos de corte. In: LOBATO, J.F.P.; BARCELLOS, J.O.J.; KESSLER, A.M.(Eds.) Produção de bovinos de corte. 1.ed. Porto Alegre: Edipucrs, 1999. p.77-96.

ROCHA, M.G.; PILAU, A.; SANTOS, D.T. et al. Desenvolvimento de bezerras de corte submetidas a diferentes sistemas alimentares. Revista Brasileira de Zootecnia, v.33, n.6, p.2123-2131, 2004 (supl.2).

ROVIRA, J. Manejo nutritivo de los rodeos de cria en pastoreo. Montevideo: Hemisferio Sur, 1996. 288p.

RYAN, W.J. Compensatory growth in cattle and sheep. Nutritional Abstracts (Series B), v.60, n.9, p.653-664, 1990.

STATISTICAL ANALYSIS SYSTEM - SAS. SAS - Language reference. Version 6.08. Cary: 1990. 1042p.

SAWYER, G.J.; BARKER, D.J.; MORRIS, R.J. Performance of young breeding cattle in commercial herds in the south-west of Western Australia. 1. Liveweight, body condition, conception and fertility in heifers. Australian Journal Experimental Agriculture, v.31, n.4, p.431-441, 1991.

STEEL, R.G.D.; TORRIE, J.H. Bioestadística: Principios y Procedimientos. Cidade do México: McGraw Hill, 1989. 622p.

STRECK, E.V.; KÄMPF, N.; DALMOLIN, R.S.D. et al. Solos do Rio Grande do Sul. 1.ed. Porto Alegre: Universidade Federal do Rio Grande do Sul, 2002. 107p.

Van SOEST, P.J. Nutrition ecology of the ruminant. 2.ed. New York: Cornell University, 1994. 476p.

VIEIRA, A.; LOBATO, J.F.P.; CÔRREA, E.S. et al. Desenvolvimento e desempenho reprodutivo de novilhas Nelore criadas a pasto nos cerrados do Centro-Oeste brasileiro. Revista Brasileira de Zootecnia, v.35, n.1, p.186-192, 2006. 